\title{
The accuracy of $A b$ Initio Calculations without $A b$ Initio Calculations for charged systems: Kriging Predictions of Atomistic Properties for lons in Aqueous Solutions
} DOI:

$10.1063 / 1.5022174$

\section{Document Version}

Accepted author manuscript

Link to publication record in Manchester Research Explorer

Citation for published version (APA):

Di Pasquale, N., Davie, S., \& Popelier, P. (2018). The accuracy of Ab Initio Calculations without Ab Initio Calculations for charged systems: Kriging Predictions of Atomistic Properties for lons in Aqueous Solutions. The Journal of chemical physics, 148(24). https://doi.org/10.1063/1.5022174

\section{Published in:}

The Journal of chemical physics

\section{Citing this paper}

Please note that where the full-text provided on Manchester Research Explorer is the Author Accepted Manuscript or Proof version this may differ from the final Published version. If citing, it is advised that you check and use the publisher's definitive version.

\section{General rights}

Copyright and moral rights for the publications made accessible in the Research Explorer are retained by the authors and/or other copyright owners and it is a condition of accessing publications that users recognise and abide by the legal requirements associated with these rights.

\section{Takedown policy}

If you believe that this document breaches copyright please refer to the University of Manchester's Takedown Procedures [http://man.ac.uk/04Y6Bo] or contact uml.scholarlycommunications@manchester.ac.uk providing relevant details, so we can investigate your claim.

\section{OPEN ACCESS}




\title{
The accuracy of $\boldsymbol{A b}$ Initio Calculations without $\boldsymbol{A} \boldsymbol{b}$ Initio Calculations for charged systems: Kriging Predictions of Atomistic Properties for lons in Aqueous Solutions
}

\author{
Nicodemo Di Pasqualeף, Stuart J Davie, and Paul LA Popelier* \\ *Manchester Institute of Biotechnology (MIB), 131 Princess Street, Manchester M1 7DN, Great Britain \\ and School of Chemistry, University of Manchester, Oxford Road, Manchester M13 9PL, Great Britain \\ "current affiliation: Department of Mathematics, University of Leicester, University Rd, \\ Leicester LE1 7RH, Great Britain
}

Using the machine learning method kriging we predict the energies of atoms in ion-water clusters, consisting of either $\mathrm{Cl}^{-}$or $\mathrm{Na}^{+}$surrounding by a number of water molecules (i.e. without $\mathrm{Na}^{+} \mathrm{Cl}^{-}$ interaction). These atoms energies are calculated following the topological energy partitioning method called Interacting Quantum Atoms (IQA). Kriging predicts atomic properties (in this case IQA energies) by a model that has been trained over a small set of geometries with known property values. Results presented here are part of the development of an advanced type of force field, called FFLUX, which offers quantum mechanical information to molecular dynamics simulations without the limiting computational cost of $a b$ initio calculations. Results reported for the prediction of the IQA components of the energy in the test set exhibit an accuracy of a few $\mathrm{kJ} / \mathrm{mol}$, corresponding to an average error of less than 5\%, even when a large cluster of water molecules surrounding an ion is considered. lons represent an important chemical system and this work shows that they can be correctly taken into account in the framework of FFLUX force field. 


\section{INTRODUCTION}

Ion solvation is fundamental in many organic, biochemical and inorganic processes ${ }^{1,2}$, including nucleation and the folding of proteins and $\mathrm{DNA}^{1,3,4}$. Despite its critical role in many chemical processes, a general and reliable model for the quantitative description of ion solutions remains out of reach and is still an active field of research ${ }^{5-7}$. The key barrier to accurate calculations in ionic solutions is the modelling of, many-body interactions that an ion experiences with its surrounding system. As system size increases, these interactions quickly become intractable by ab initio Molecular Dynamics (MD), while coarser grained methods are not accurate enough to reliably reproduce bulk properties ${ }^{8}$.

To overcome the challenges that ionic interactions bring to molecular modelling, we implement a machine learning method called kriging in order to describe them at a level of detail comparable to the full $a b$ initio description of the system. The use of a machine learning enhanced force field, for the MD simulation of ions, enters into the framework of FFLUX ${ }^{9}$ currently under development. The use of machine learning in the computational chemistry community is a growing field, with machine learning techniques already having shown to give a good description of atomization energies ${ }^{10}$, or increase accuracy of Density Functional Theory (DFT) calculations ${ }^{11}$. Other machine learning enhanced force fields are also currently developed in different groups ${ }^{12,13}$.

Initial work considering the application of kriging to ionic systems has been completed by Mills and Popelier ${ }^{14}$. However, this work reported only atomic multipole moments of a single, micro-solvated sodium ion. In the current article we show the application of the kriging framework to both a significantly larger $\mathrm{Na}^{+}$system in aqueous solution and an equivalent $\mathrm{Cl}^{-}$system. Moreover, for the first time, we extend the treatment beyond the electrostatic interaction. For that purpose we invoke the topological energy partitioning method Interacting Quantum Atom (IQA $)^{15}$. Results are presented for ionic, solvated clusters ranging from one to seven water molecules, each water cluster surrounding either $\mathrm{Na}^{+}$or $\mathrm{Cl}^{-}$but not both together.

\section{METHODS AND MATERIALS}

\section{A. Clusters}

Each cluster is identified by the name of the ion and the number of water molecules within. For example, $\mathrm{Cl}-\mathrm{W} 7$ refers to a system consisting of one $\mathrm{Cl}$ ion and seven water molecules. In the second part of this work we present kriging models developed for a more general system containing eight water molecules and both $\mathrm{Cl}^{-}$and $\mathrm{Na}^{+}$, which will be denoted as $\mathrm{CINa}-\mathrm{W} 8$. This system will in turn be the reference system used to demonstrate the Variable Number of Features (VNF) kriging method ${ }^{16}$. The VNF method, which will be described in detail later, is a way to extend kriging models to systems with varying dimensions. In a real system, the neighbourhood of each atom changes with time, e.g. the number of 
water molecules around an ion at any given time. Standard kriging models assume a fixed number of dimensions for the feature space (i.e. the size of the neighbourhood), while the VNF method allows to include some flexibility in the kriging models which are needed for the application to MD simulations. The systems whose predictions are obtained using VNF will be indicated by adding a " $v$ " to their name. For example, $\mathrm{vCl}-\mathrm{W} 4$ represents the chlorine ion within a cluster of four water molecules whose predictions are obtained using the VNF algorithm based on the CINa-W8 cluster. Note that we did not apply the VNF method to the less interesting cases of Cl-W1, Cl-W2, Cl-W3 and Na-W1, Na-W2, Na-W3. The robust implementation of the kriging framework to such systems represents a significant leap in the development of accurate, efficient modelling methods for realistic ionic simulations.

\section{B. Computational Details}

\section{Molecular Dynamics Simulations}

The solvated ion clusters were sampled from an MD simulation carried out by the program GROMACSs (version 5.0.4) ${ }^{17,18}$. The simulated system is composed of $54 \mathrm{NaCl}$ ion pairs surrounded by 2072 water molecules. The time step was set at $1 \mathrm{fs}$ and the cut-off for dispersion interactions at $10 \AA$. Long-range electrostatics were calculated by Particle Mesh Ewald summation (PME) with a Fourier spacing of $1.5 \AA$ and fourth-order interpolation ${ }^{19,20}$. Equilibration and simulations were performed in the isothermal-isobaric (NPT) ensemble, with a Berendsen thermostat maintaining the temperature at $300 \mathrm{~K}$ and with a coupling time $\tau_{\mathrm{T}}=0.1 \mathrm{ps}$. The Berendsen barostat used isotropic pressure coupling with a reference pressure set at 1 bar and with a pressure coupling time $\tau_{p}=3.0$ ps. Equilibration was performed for 3 ns until properties converged. Production simulations were run for 10 ns. The force field ${ }^{21}$ employed for the water molecules was SPC/E while the GROMOS96 43a1p force field ${ }^{22}$ was used for the ions. Cluster geometries are extracted from the trajectory and used to create the test and training sets. Trajectories are saved every picosecond and an in-house program checks for the neighbours of each ion at each snapshot. If the neighbours of the selected atoms are consistent with our requirements then that particular configuration is saved. Imagine an example where we want to extract geometries for Na-W4. Our program looks for every $\mathrm{Na}^{+}$ion that has four water molecules as its first neighbours. The configurations of such systems are saved. The program stops when enough configurations are found that meet our requirements. The total number of configurations collected is equal to the sum of the number of training points, $N_{t}$, and the number of prediction points, $N_{p}$, that we want to use. Eventually, the set of total configurations is randomly split in training set and test set. 


\section{Ab initio Calculations (wave function generation)}

Regardless of whether they end up in the training set or test set, water-ion clusters were submitted to an in-house script called $\mathrm{GAIA}^{23}$, where each geometry was input to the ab initio program ${ }^{24}$ GAUSSIAN09 at the B3LYP/6-311+G(2d,2p) level of theory in order to obtain cluster wave functions. This level of theory is the same as that used before ${ }^{14}$ by Mills and Popelier in their purely electrostatic kriging work of microhydrated $\mathrm{Na}^{+}$. Note that the current approach does not introduce any basis set superposition error because this effect arises only when energies of supermolecular and monomeric wave functions are subtracted (and small basis sets are used). There is no such reference to monomeric wave functions in the current approach: all necessary information comes from the clusters themselves (without reference to water monomers). We also note that the compatibility of DFT with IQA was ensured by a method explained in great detail elsewhere ${ }^{25}$.

Wave function files were then processed by the topological partitioning program AIMAll ${ }^{26}$ to obtain atomic IQA-partitioned energies:

$$
E_{\text {tot }}(A)=E_{\text {intra }}(A)+V_{x c}\left(A, A^{\prime}\right)+V_{c l}\left(A, A^{\prime}\right)
$$

where $A^{\prime}$ refers to the atomic environment of a given atom $A$ (where $A^{\prime}$ excludes $A$ ), $\mathrm{E}_{\text {intra }}(A)$ is the intraatomic energy (sometimes called self-energy $\left.{ }^{27}\right)$, while $V_{x c}\left(A, A^{\prime}\right)$ and $V_{c l}\left(A, A^{\prime}\right)$ are the two inter-atomic energy components, namely the exchange-correlation energy and the classical electrostatic energy, respectively ${ }^{28}$. Note that we adhere to the standard IQA notation of $V_{c l}$, where the subscript refers to "classical" and of course not to chlorine. From here, each configuration (input) and its corresponding energies (output) are used as training points for our kriging program FEREBUS ${ }^{29}$, 30 . This program calculates the so-called hyperparameters $\boldsymbol{\theta}$ and $\mathbf{p}$ of the models, as shown in Eq. (2). Kriging is an interpolating predictor, which assumes continuity of the data that it models. As such, two close points in input space will show a higher likelihood of having similar values of a property when compared to points far away. The value of the atomic property $y\left(\mathbf{x}^{*}\right)$ at an unknown position $\mathbf{x}^{*}$ is given ${ }^{31}$ by

$$
y\left(\mathbf{x}^{*}\right)=\mu+\sum_{j=1}^{N_{t}} a_{j} \exp \left[-\sum_{k=1}^{N_{f}} \theta_{k}\left|x_{k}^{*}-x_{k}^{j}\right|^{p_{k}}\right]
$$

where $\mu$ represents the global mean estimated from the training points, $\mathbf{a}$ is the vector that contains the information about the training set used in the training, $N_{f}$ is the number of features (i.e. inputs) of the problem, and $N_{t}$ is the number of training points in the training set. Many more equations behind the kriging method have been published in previous work, in most detail in ref. ${ }^{32}$.

Model training sets varied in size from 1500 to 2200 training points, depending on the number of atoms in each cluster, and the models were validated on an external test set of 2000 points (1000 points 
for the VNF systems), which was independently sampled. Figure 1 show a flowchart that summarizes the section above.

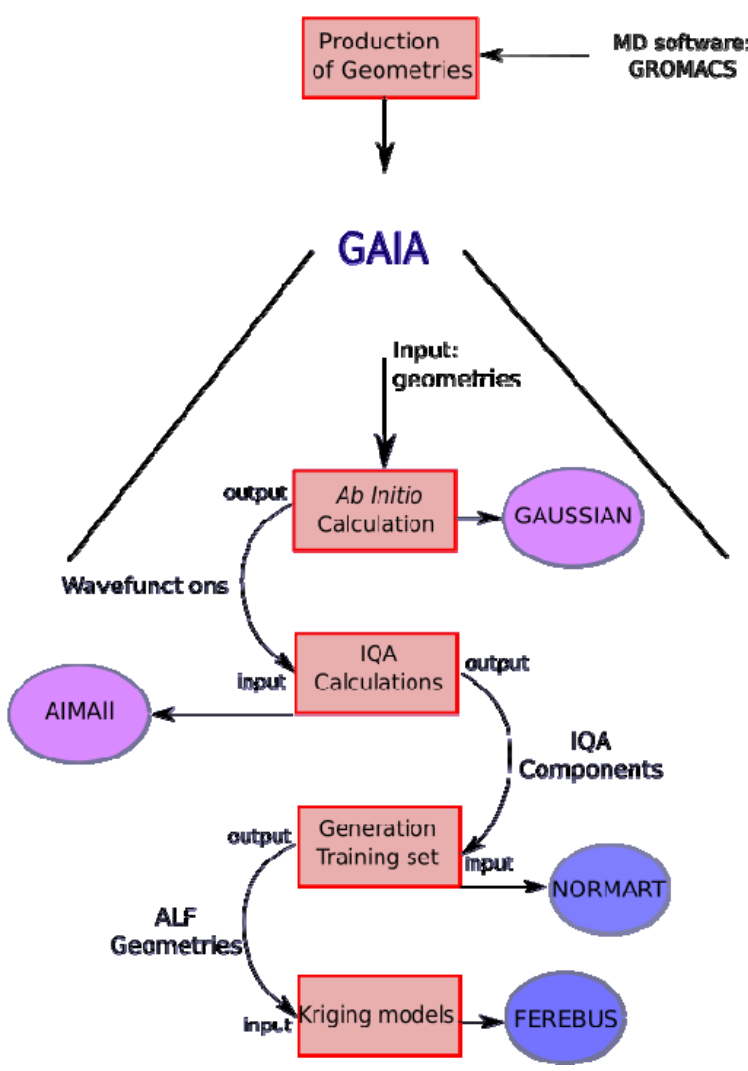

Figure 1. Flowchart of the operations needed to obtain kriging models. The in-house GAIA script calls the programs GAUSSIAN, AIMALL, NORMART and FEREBUS and organises the data stream (input/output). The geometries are obtained outside GAIA and represent the starting input that will lead to the kriging models. We represent with different colours the in-house programs: FEREBUS and NORMART (dark blue) and the external programs AIMALL and GAUSSIAN (purple).

\section{Coordinate System}

In order to apply configurational inputs as machine learning features, a suitable coordinate frame must be chosen. In this work we use an atomic local frame (ALF) ${ }^{23,33}$, depicted in Figure 2, which has proven successful in the prediction of energies for other small clusters ${ }^{34}$, although other coordinate representations exist ${ }^{10,11,35}$. The ALF basis is a right-handed coordinate system which, in the current work, is always centred on the ion of interest, from now on referred to as the 'central' ion. The direction of the $\mathrm{x}$-axis is taken from the vector connecting the central atom with another atom in the system (from 
now the 'second' atom). We define the second atom to always be the closest oxygen to the central ion. The $y$-axis is perpendicular to the $x$-axis and positioned on the plane identified by the central ion, the second atom and a third atom. The third atom is always the second closest oxygen to the central ion. Finally, the $z$-axis is taken as the vector perpendicular to the $x$ - and $y$-axis. The position of all other atoms in the system can be defined by spherical polar coordinates in the ALF coordinate frame. The ALF basis will always be built with one ion and two water molecules, even when other ions are present, except in the $\mathrm{Cl}-\mathrm{W} 1$ and Na-W1 systems, where the closest hydrogen is used to define the ALF y-axis.

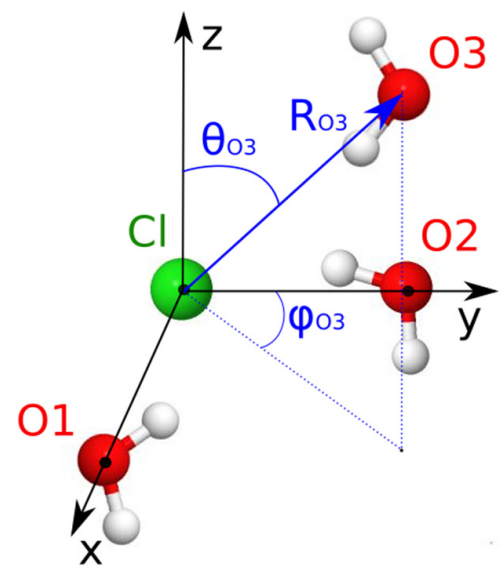

Figure 2. Coordinate frame and three kriging features of a chlorine atom and its water neighbours. The $\mathrm{x}$-axis of the system is defined by the $\mathrm{Cl}-\mathrm{O} 1$ distance, and the xy-plane is defined by the $\mathrm{Cl}-\mathrm{O} 1$ and $\mathrm{Cl}-\mathrm{O} 2$ vectors. The three features shown correspond to the position of atom $\mathrm{O} 3$ in the $\mathrm{Cl}$ coordinate system, expressed by means of spherical polar coordinates.

\section{Variable Number of Features}

In a MD simulation the immediately surrounding environment is not fixed in time, and hence can include various combinations of water molecules and other ions. Different cluster sizes can be handled by using the VNF approach. The VNF framework builds a single kriging model capable of describing systems with lower dimensionality, avoiding the requirement of different kriging models for each possible environment. Results reported here represent the first application of the variable number of features technique.

Although the model is called "variable", once the reference system has been defined the total number of features does not change. Instead, what changes is the dimensionality of the problem to which we are applying our reference system; the VNF model employs the features of a larger system to 
describe a system with lower dimensionality. As the lower-dimensional system will have extra features (inherited from the higher-dimensional system), we will call these extra features dummy features. As an example, modelling the $\mathrm{Cl}$-W4 system using a $\mathrm{NaCl}$-W8 cluster as a reference system will result in dummy features representing the four extra water molecules and the extra $\mathrm{Na}^{+}$ion that the reference system possesses. In this case, each additional water molecule contributes nine additional features $\left(R_{0}, \theta_{0}, \phi_{0}\right.$, $\left.R_{H 1}, \theta_{H 1}, \phi_{H 1}, R_{H 2}, \theta_{H 2}, \phi_{H 2}\right)$, while the extra ion $(\mathrm{X}=\mathrm{Cl}, \mathrm{Na})$ contributes three additional features $\left(R_{X}, \theta_{X}, \phi_{X}\right)$. Following the VNF method ${ }^{16}$ we choose a single feature and assign it a value outside the sampled domain for each water molecule, and for the extra ion. The selected feature is always the distance $R_{O}$ for each extra water molecule and $R_{x}$ for the extra ion. Next, we assign to the remaining features (eight for each extra water molecule and two for the extra ion) a mean value obtained by averaging the features among the training points we have. A more detailed description can be found in reference ${ }^{16}$. One important matter to remember in the construction of the VNF model for a system is that the extended system must mimic exactly the smaller system it encloses. This is to say that, if we choose a system centred on the $\mathrm{Cl}$ anion with the water molecules ordered against the distance with respect the central ion (e.g. Cl-W7), then the $\mathrm{NaCl}-\mathrm{W} 8$ must be built in the same way, with the $\mathrm{Cl}$ ion at the centre and all the water molecules ordered against the distance with respect to the $\mathrm{Cl}$. The position of the Na will not have any constraint. The same must be done for the Na cation, using a different set of configurations where the water molecules are ordered with respect to the $\mathrm{Na}$ ion. A sketch of the VNF framework applied to $\mathrm{Cl}-\mathrm{W} 7$ system is shown in Figure 3.

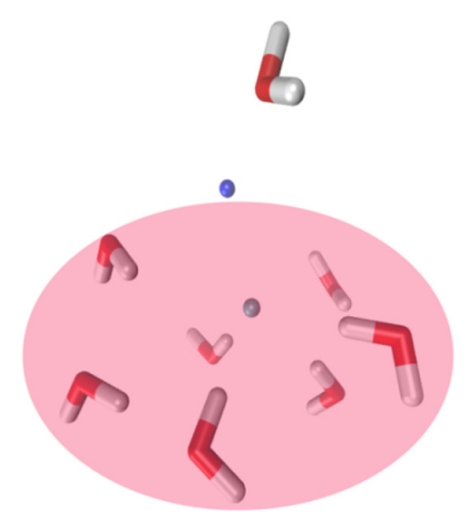

Figure 3. Example of system (Cl-W7) considered in the VNF framework. The larger system is represented by the CINa-W8 cluster (with the green sphere as the $\mathrm{Cl}^{-}$ion and the blue sphere as the $\mathrm{Na}^{+}$ion). The system with smaller dimensionality, i.e. Cl-W7, which has real features, is shown inside the red region. The $\mathrm{Na}^{+}$ion and the water molecule outside this region represent the dummy features. 


\section{Results and Discussion}

\section{A. Fixed Number of Features.}

Table 1 reports the prediction errors and $\mathrm{q}^{2}$ metric ${ }^{36}$ for the three types of atomic energy, $\mathrm{E}_{\text {intra }}(\mathrm{Cl})$, $\mathrm{V}_{\mathrm{xc}}\left(\mathrm{Cl}, \mathrm{A}^{\prime}\right)$ and $\mathrm{V}_{\mathrm{cl}}\left(\mathrm{Cl}, \mathrm{A}^{\prime}\right)$, evaluated in the 7 aqueous $\mathrm{Cl}$ systems. Across all models the maximum Mean Absolute Error is approximately $1 \mathrm{~kJ} / \mathrm{mol}$ or less. Furthermore, the $\mathrm{q}^{2}$ metric is close to one in almost all cases presented (especially in the $V_{c l}$ results), showing that models obtained have a high predictive ability. The lowest value of $\mathrm{q}^{2}$ is obtained for $\mathrm{E}_{\text {intra }}(\mathrm{Cl})$ in the $\mathrm{Cl}-\mathrm{W} 3$ case, which is well above the $\mathrm{q}^{2}=0.5$ threshold necessary to consider the predictions obtained by kriging better than those obtained by using a naïve predictor ${ }^{36}$. Given the fact that this value seems to be an outlier in the set of predictions for the $\mathrm{Cl}$ system, it seems reasonable to conclude that this particular value is mostly due to the particular training set considered obtained with a random sampling. Other sampling techniques exist that can increase the performance of the predictions ${ }^{37}$. Both the Mean Absolute Error and the Max Absolute Error generally increase with increasingly cluster size although there are exceptions to this trend. Finally, the Max Absolute Error for $\mathrm{V}_{\mathrm{cl}}\left(\mathrm{Cl}, \mathrm{A}^{\prime}\right)$ is always smaller, for each of the 7 clusters, than the corresponding value for $\mathrm{V}_{\mathrm{xc}}\left(\mathrm{Cl}, \mathrm{A}^{\prime}\right)$ and $\mathrm{E}_{\text {intra }}(\mathrm{Cl})$. The last column of Table 1 , denoted $\Delta$ err, represents the difference between the mean true value of each property in the test set and the mean value predicted by each of the kriging models. With the only exception of $\mathrm{Cl}-\mathrm{W} 4$ that reports a value of $\Delta$ err $=1.5 \mathrm{~kJ} / \mathrm{mol}$, this quantity is zero or approximately zero in all the other cases considered. This indicates that the behaviour of the system is correctly captured by the kriging models, which is essential for a model to be used in a MD simulation.

\begin{tabular}{|c|c|c|c|c|c|}
\hline \multicolumn{6}{|c|}{$V_{c l}\left(A, A^{\prime}\right) / 2$} \\
\hline & $q^{2}$ & $\begin{array}{c}\text { Mean Absolute } \\
\text { Error } \\
(\mathrm{kJ} / \mathrm{mol})\end{array}$ & $\begin{array}{c}\text { Max Absolute } \\
\text { Error } \\
(\mathrm{kJ} / \mathrm{mol})\end{array}$ & $\begin{array}{c}\text { Mean True Value } \\
(\mathrm{kJ} / \mathrm{mol})\end{array}$ & $\Delta e r r(\mathrm{~kJ} / \mathrm{mol})$ \\
\hline $\mathrm{Cl}-\mathrm{W} 1$ & 0.942 & 0.2 & 2.2 & 6.3 & 0.0 \\
\hline $\mathrm{Cl}-\mathrm{W} 2$ & 0.959 & 0.3 & 4.8 & 2.1 & 0.1 \\
\hline $\mathrm{Cl}-\mathrm{W} 3$ & 0.970 & 0.3 & 4.0 & -4.2 & 0.0 \\
\hline $\mathrm{Cl}-\mathrm{W} 4$ & 0.980 & 0.4 & 3.6 & -10.9 & 0.0 \\
\hline $\mathrm{Cl}-\mathrm{W} 5$ & 0.986 & 0.5 & 8.3 & -17.1 & -0.0 \\
\hline $\mathrm{Cl}-\mathrm{W} 6$ & 0.990 & 0.5 & 9.7 & -22.9 & 0.0 \\
\hline Cl-W7 & 0.991 & 0.6 & 7.0 & -27.0 & 0.0 \\
\hline \multicolumn{6}{|c|}{$V_{x c}\left(A, A^{\prime}\right) / 2$} \\
\hline
\end{tabular}




\begin{tabular}{|l|c|c|c|c|c|}
\hline Cl-W1 & 0.978 & 0.1 & 7.6 & -27.6 & 0.1 \\
\hline Cl-W2 & 0.979 & 0.3 & 5.8 & -37.6 & 0.0 \\
\hline Cl-W3 & 0.969 & 0.4 & 6.5 & -41.5 & 0.0 \\
\hline Cl-W4 & 0.959 & 0.5 & 7.8 & -43.0 & -1.5 \\
\hline Cl-W5 & 0.932 & 0.6 & 13.0 & -43.4 & 0.0 \\
\hline Cl-W6 & 0.918 & 0.6 & 12.4 & -43.4 & 0.0 \\
\hline Cl-W7 & 0.925 & 0.6 & 9.3 & -43.0 & 0.01 \\
\hline & & & $E_{\text {intra }}$ & & 0.0 \\
\hline Cl-W1 & 0.902 & 0.1 & 3.7 & -1208479.3 & 0.0 \\
\hline Cl-W2 & 0.826 & 0.5 & 6.2 & -1208460.5 & 0.0 \\
\hline Cl-W3 & 0.654 & 0.9 & 9.4 & -1208454.1 & 0.0 \\
\hline Cl-W4 & 0.760 & 1.0 & 9.5 & -1208452.7 & 0.0 \\
\hline Cl-W5 & 0.876 & 1.1 & 8.2 & -1208453.2 & 0.0 \\
\hline Cl-W6 & 0.920 & 1.1 & 18.8 & -1208454.3 & 0.0 \\
\hline Cl-W7 & 0.939 & 1.2 & 11.7 & -1208455.1 & \\
\hline
\end{tabular}

Table 1. Validation statistics for predictions of the three types of atomic energy contributions $\left(V_{c l}\left(A, A^{\prime}\right) / 2\right.$, $V_{x c}\left(A, A^{\prime}\right) / 2$ and $\left.E_{\text {intra }}\right)$ of the hydrated $\mathrm{Cl}$ anion, with each cluster size represented by a separate model. $\Delta e r r$ is the difference between the mean true value of the properties and the mean value predicted by each kriging model.

Table 2 provides the same type of validation analysis but now for the sodium cation. The first consistent and noticeable difference between the sodium and chlorine predictions is that the $q^{2}$ values are generally higher for the sodium. This observation is especially true for the intra-atomic energy contribution. Again generally, the Mean Absolute Error is of similar size between the sodium cation and the chlorine anion although this error can be several factors smaller (even more than an order of magnitude) for sodium compared to chlorine. A major difference between the patterns of Max Absolute Errors in the sodium data compared to the chlorine data is that $V_{x c}\left(N a, A^{\prime}\right)$ and $E_{\text {intra }}(\mathrm{Na})$ are much lower than for $\mathrm{Cl}$. However, the Max Absolute Errors for $\mathrm{V}_{\mathrm{cl}}\left(\mathrm{Na}, \mathrm{A}^{\prime}\right)$ rise more rapidly with cluster size than for $\mathrm{V}_{\mathrm{cl}}\left(\mathrm{Cl}, \mathrm{A}^{\prime}\right)$. 


\begin{tabular}{|c|c|c|c|c|c|}
\hline \multicolumn{6}{|c|}{$V_{c l}\left(A, A^{\prime}\right) / 2$} \\
\hline & $q^{2}$ & $\begin{array}{c}\text { Mean } \\
\text { Absolute error } \\
(\mathrm{kJ} / \mathrm{mol})\end{array}$ & $\begin{array}{c}\text { Max Absolute } \\
\text { error } \\
(\mathrm{kJ} / \mathrm{mol})\end{array}$ & $\begin{array}{l}\text { Mean True Value } \\
(\mathrm{kJ} / \mathrm{mol})\end{array}$ & $\Delta e r r(\mathrm{~kJ} / \mathrm{mol})$ \\
\hline $\mathrm{Na}-\mathrm{W} 1$ & 0.996 & 0.05 & 0.7 & -18.2 & 0.0 \\
\hline $\mathrm{Na}-\mathrm{W} 2$ & 0.997 & 0.08 & 3.9 & -35.5 & 0.0 \\
\hline Na-W3 & 0.996 & 0.1 & 5.6 & -51.1 & 0.0 \\
\hline $\mathrm{Na}-\mathrm{W} 4$ & 0.997 & 0.2 & 8.9 & -64.7 & 0.0 \\
\hline Na-W5 & 0.998 & 0.2 & 4.0 & -76.2 & 0.0 \\
\hline Na-W6 & 0.997 & 0.4 & 10.1 & -81.1 & 0.0 \\
\hline Na-W7 & 0.991 & 0.5 & 23.1 & -83.1 & 0.0 \\
\hline \multicolumn{6}{|c|}{$V_{x c}\left(A, A^{\prime}\right) / 2$} \\
\hline $\mathrm{Na}-\mathrm{W} 1$ & 0.974 & 0.02 & 0.9 & -1.3 & 0.0 \\
\hline $\mathrm{Na}-\mathrm{W} 2$ & 0.970 & 0.04 & 0.7 & -1.8 & 0.0 \\
\hline Na-W3 & 0.969 & 0.05 & 0.5 & -2.1 & 0.0 \\
\hline $\mathrm{Na}-\mathrm{W} 4$ & 0.963 & 0.05 & 1.5 & -2.3 & 0.0 \\
\hline $\mathrm{Na}-\mathrm{W} 5$ & 0.959 & 0.06 & 0.8 & -2.4 & 0.0 \\
\hline Na-W6 & 0.963 & 0.06 & 0.6 & -2.4 & 0.0 \\
\hline Na-W7 & 0.956 & 0.05 & 1.2 & -2.5 & 0.0 \\
\hline \multicolumn{6}{|c|}{$E_{\text {INTRA }}$} \\
\hline Na-W1 & 0.994 & 0.02 & 0.4 & -425567.0 & 0.1 \\
\hline $\mathrm{Na}-\mathrm{W} 2$ & 0.992 & 0.04 & 1.0 & -425568.1 & 0.0 \\
\hline Na-W3 & 0.987 & 0.05 & 0.8 & -425568.7 & 0.0 \\
\hline Na-W4 & 0.977 & 0.06 & 1.5 & -424441.5 & 0.0 \\
\hline $\mathrm{Na}-\mathrm{W} 5$ & 0.976 & 0.07 & 0.9 & -42441.6 & 0.1 \\
\hline $\mathrm{Na}-\mathrm{W} 6$ & 0.976 & 0.07 & 0.8 & -424441.7 & 0.1 \\
\hline Na-W7 & 0.970 & 0.08 & 1.6 & -424441.7 & 0.1 \\
\hline
\end{tabular}

Table 2. Validation statistics for predictions of the three types of atomic energy contributions $\left(V_{c l}\left(A, A^{\prime}\right) / 2\right.$, $V_{x c}\left(A, A^{\prime}\right) / 2$ and $\left.E_{\text {intra }}\right)$ of the hydrated Na cation, with each cluster size represented by a separate model. $\Delta e r r$ is the difference between the mean true value of the properties and the mean value predicted by eachkriging model. 
The error analysis now moves beyond overall measures of performance (e.g. mean, maximum) to a more complete display of behaviour in energy errors. This more extensive analysis is carried out by means of the so-called S-curve, which is a cumulative energy profile. Figure 4 displays the S-curves of the $\mathrm{V}_{\mathrm{cl}}, \mathrm{V}_{\mathrm{xc}}$ and $\mathrm{E}_{\text {intra }}$ prediction errors for the seven $\mathrm{Cl}$-anion system sizes. Figure 5 does the same for the Nacation systems. It is easy to read such S-curves by fixing a particular energy error $(\varepsilon)$ and seeing where the corresponding vertical line intersects an S-curve of interest. For example, in the $\mathrm{V}_{\mathrm{cl}} \mathrm{S}$-curve of the $\mathrm{Cl}^{-}$ $\left(\mathrm{H}_{2} \mathrm{O}\right)_{7}$ cluster, just over $80 \%$ of all test set geometries return an error of $1 \mathrm{~kJ} / \mathrm{mol}$ or less. The more an Scurve of a model moves to the left the more accurate that model. For all three types of energy the Scurves move systematically to the left each time a water molecule is removed from the $\mathrm{Cl}^{-}\left(\mathrm{H}_{2} \mathrm{O}\right)_{n}$ cluster. This trend is expected because the smaller clusters are easier to model, i.e. more (external) test geometries will yield low errors. For both the cationic and anionic systems, the vast majority (at least $80 \%$ but more typically $95 \%$ ) of prediction errors fall below $1 \mathrm{~kJ} / \mathrm{mol}$. The only exception is the $\mathrm{E}_{\text {intra }}$ error, where this threshold has to be increased from $1 \mathrm{~kJ} / \mathrm{mol}$ to $2.5 \mathrm{~kJ} / \mathrm{mol}$. Finally, the S-curves for the sodium cation are overall superior to those of the chlorine anion. The former show superb errors for the more challenging $E_{\text {intra }}$ energies because all test geometries for all seven systems nearly hit the $100 \%$ ceiling at $0.4 \mathrm{~kJ} / \mathrm{mol}$ (or $0.1 \mathrm{kcal} / \mathrm{mol})$.
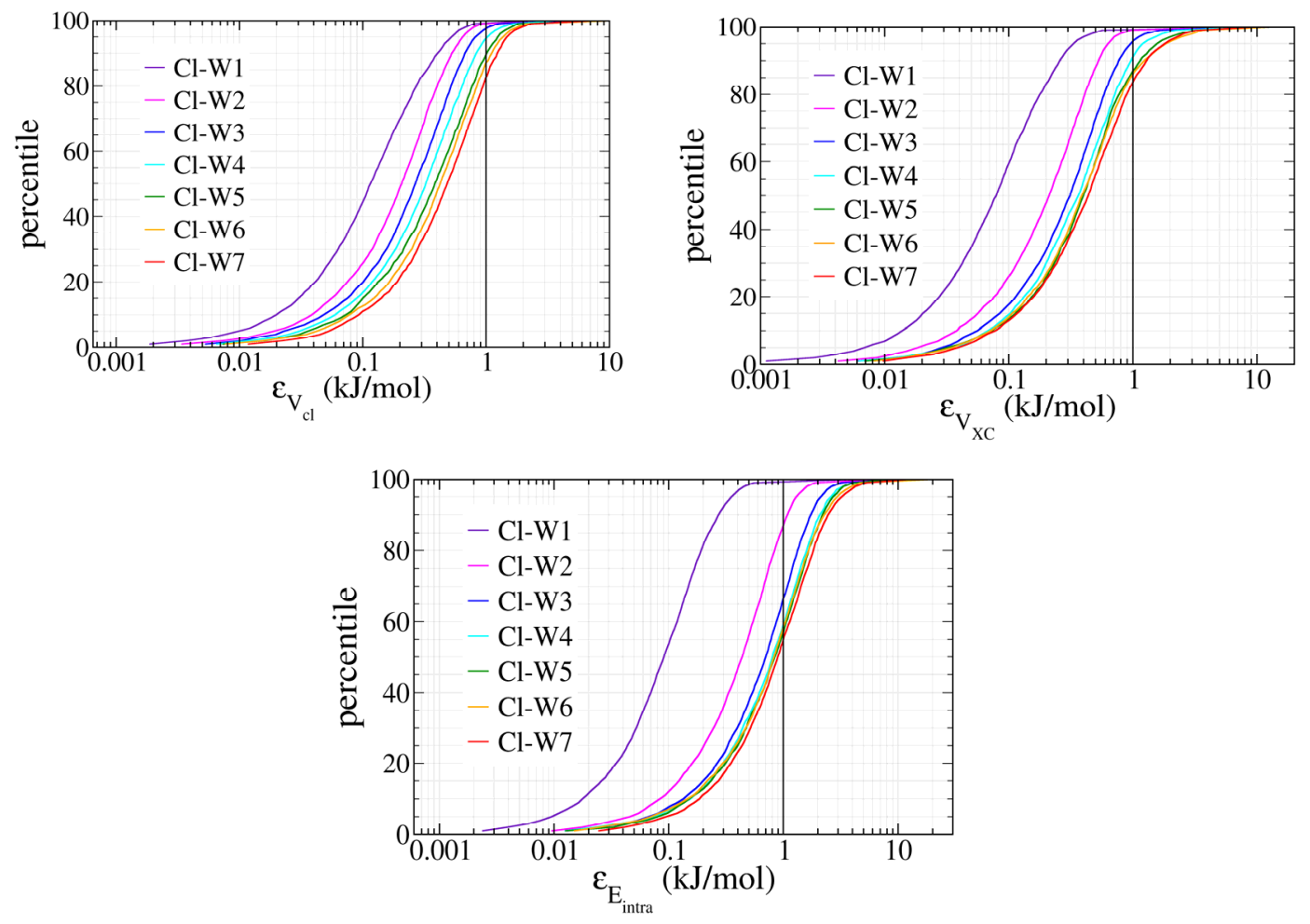

Figure 4. S-curves for the three IQA energy components, $V_{c l}\left(A, A^{\prime}\right) / 2, V_{x c}\left(A, A^{\prime}\right) / 2$ and $E_{\text {intra, }}$ one for each of the $\mathrm{Cl}$ anion-water systems. 

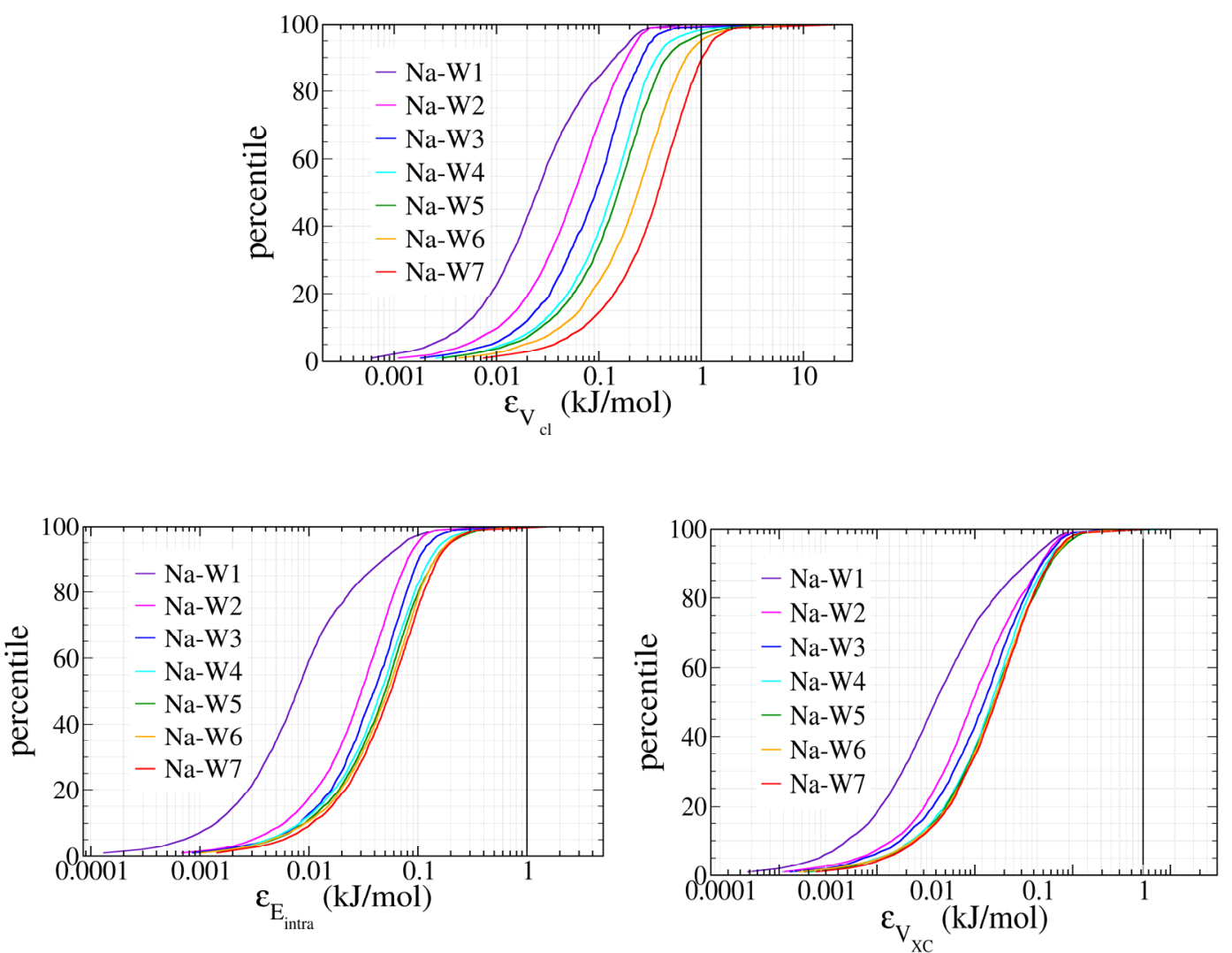

Figure 5. $S$-curves for the three IQA energy components, $V_{c 1}\left(A, A^{\prime}\right) / 2, V_{x c}\left(A, A^{\prime}\right) / 2$ and $E_{\text {intra, }}$ one for each of the Na cation-water systems.

Figures 4 and 5 clearly illustrate a "bunching effect", i.e. the collapsing of all S-curves onto the one most on the right. This effect was already observed in our previous work ${ }^{14}$ on the kriging prediction of the electrostatic interaction for $\mathrm{Na}^{+}$. One reason for this effect can be found in the fact that by increasing the number of water molecules from one to two the environment seen by the ion is very different. If we add more water molecules we are filling the first solvation shell of the ion, and hence the environment seen by the ion does not change too much. As an example, the first solvation shell for $\mathrm{Cl}^{-}$is around 6 water molecules ${ }^{38}$, which is consistent with what we observe in Fig. 3. 


\section{B. Variable Number of Features.}

All models reported so far include fixed sized clusters, in contrast to the fluctuating number of interactions that an atom in an MD simulation will normally witness at each time step. Therefore, the development of the VNF method constitutes an essential step towards the creation of a force field for MD simulation based on machine learning techniques. In this section we analyse the performance of the VNF framework, described in Section 2.D, and applied to chlorine and sodium clusters of sizes varying from four to seven water molecules.

Table 3 presents the prediction errors and the $\mathrm{q}^{2}$ metric for the $\mathrm{Cl}$ system, modelled using the VNF approach. Again, the Mean Absolute Error is approximately $1 \mathrm{~kJ} / \mathrm{mol}$ (or lower) for all systems considered, while the $\mathrm{q}^{2}$ metric shows the strong performance of the kriging predictor relative to a naïve predictor. Although the Maximum Absolute Error for predictions of the $\mathrm{V}_{\mathrm{cl}}\left(\mathrm{A}, \mathrm{A}^{\prime}\right)$ of the $\mathrm{vCl} 6$ system is relatively high, Figure 6 shows this to be an outlier. In fact, the S-curve of the error on the $V_{c l}\left(A, A^{\prime}\right)$ predictions for $\mathrm{vCl}-\mathrm{W} 6$ shows that the number of errors smaller than $11.7 \mathrm{~kJ} / \mathrm{mol}$ is almost $100 \%$. Furthermore, it is worth noting that the number of training points used here, represent a trade-off between accuracy and speed of calculation, and by increasing the number of training points, greater accuracy will be obtained. Figure 6 displays the prediction-error distributions of the 3 types of IQA energy contribution in S-curve form, with over half of all errors under $1 \mathrm{~kJ} / \mathrm{mol}$. In fact, over $80 \%$ of the errors are below $1 \mathrm{~kJ} / \mathrm{mol}$ for $\mathrm{V}_{\mathrm{cl}}\left(A, A^{\prime}\right)$, and over $60 \%$ of the errors are below the same threshold for $E_{\text {intra. }}$. 


\begin{tabular}{|c|c|c|c|c|c|}
\hline \multicolumn{6}{|c|}{$V_{c l}\left(A, A^{\prime}\right) / 2$} \\
\hline & $q^{2}$ & $\begin{array}{c}\text { Mean Absolute } \\
\text { error } \\
(\mathrm{kJ} / \mathrm{mol})\end{array}$ & $\begin{array}{c}\text { Max Absolute } \\
\text { error } \\
(\mathrm{kJ} / \mathrm{mol})\end{array}$ & $\begin{array}{c}\text { Mean True Value } \\
(\mathrm{kJ} / \mathrm{mol})\end{array}$ & $\Delta e r r(\mathrm{~kJ} / \mathrm{mol})$ \\
\hline vCl-W4 & 0.983 & 0.4 & 2.7 & -10.9 & 0.0 \\
\hline vCl-W5 & 0.988 & 0.5 & 3.1 & -17.1 & -0.1 \\
\hline vCl-W6 & 0.990 & 0.5 & 11.7 & -22.8 & 0.0 \\
\hline vCl-W7 & 0.992 & 0.6 & 4.9 & -27.0 & 0.0 \\
\hline \multicolumn{6}{|c|}{$V_{x c}\left(A, A^{\prime}\right) / 2$} \\
\hline $\mathrm{vCl}-\mathrm{W} 4$ & 0.961 & 0.5 & 6.7 & -43.0 & 0.0 \\
\hline $\mathrm{vCl}-\mathrm{W} 5$ & 0.942 & 0.5 & 6.8 & -43.4 & 0.0 \\
\hline vCl-W6 & 0.915 & 0.6 & 14.2 & -43.4 & 0.0 \\
\hline $\mathrm{vCl}-\mathrm{W} 7$ & 0.931 & 0.6 & 5.2 & -43.0 & 0.0 \\
\hline \multicolumn{6}{|c|}{$E_{\text {intra }}$} \\
\hline vCl-W4 & 0.777 & 1.0 & 6.0 & -1208452.7 & 0.0 \\
\hline vCl-W5 & 0.882 & 1.0 & 7.4 & -1208453.1 & -0.1 \\
\hline vCl-W6 & 0.923 & 1.1 & 7.3 & -1208454.2 & 0.0 \\
\hline vCl-W7 & 0.939 & 1.2 & 8.9 & -1208455.1 & 0.0 \\
\hline
\end{tabular}

Table 3. Validation statistics for predictions of the three types of atomic energy contributions $\left(V_{c l}\left(A, A^{\prime}\right) / 2\right.$, $V_{x c}\left(A, A^{\prime}\right) / 2$ and $\left.E_{\text {intra }}\right)$ of the hydrated $\mathrm{Cl}$ anion, with all cluster sizes represented by a single VNF model. $\Delta e r r$ is the difference between the mean true value of the properties and the mean value predicted by each kriging model. 

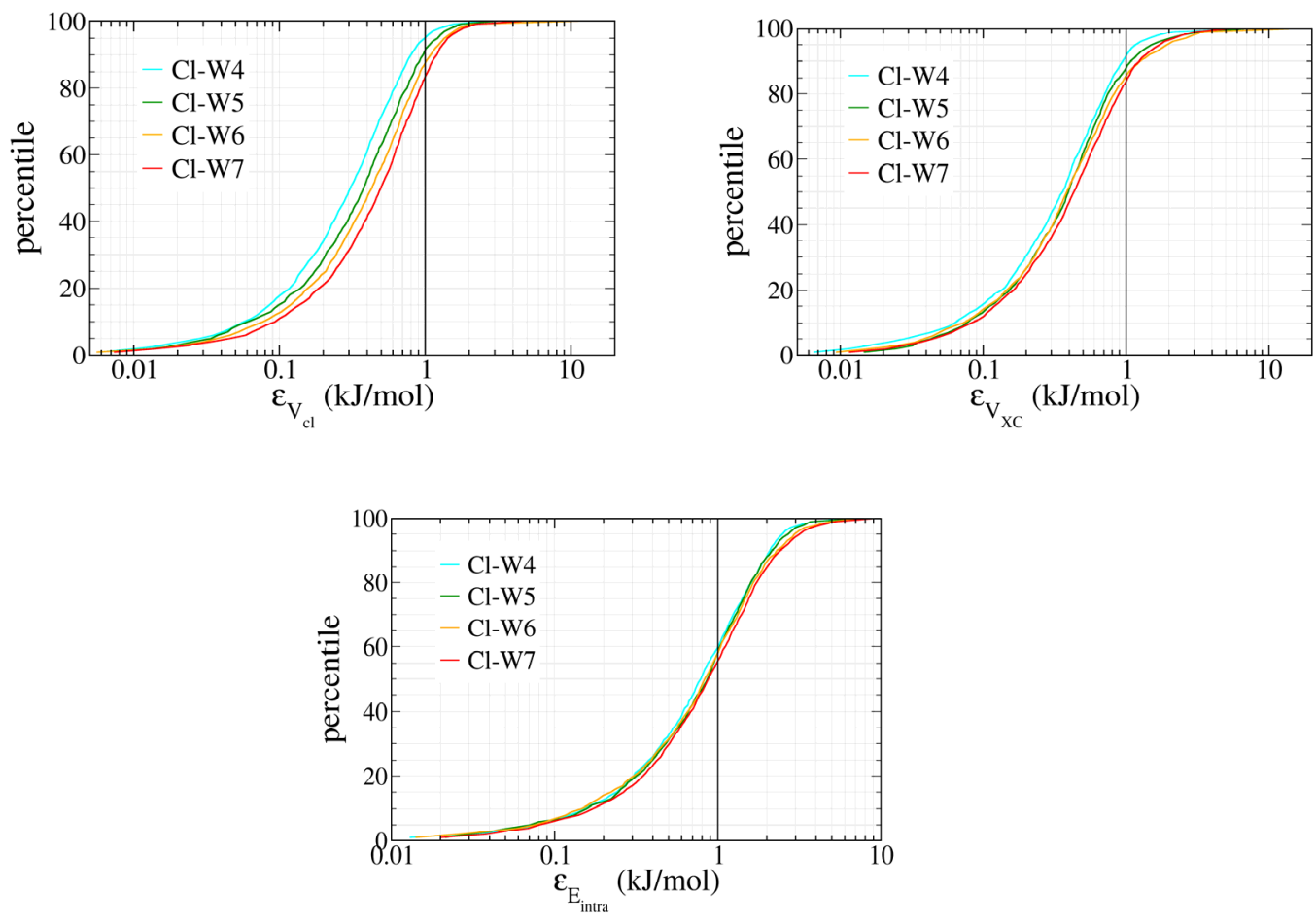

Figure 6. S-curves for the three IQA energy components, $V_{c l}\left(A, A^{\prime}\right) / 2, V_{x c}\left(A, A^{\prime}\right) / 2$ and $E_{\text {intra, }}$ for $C l$ anionwater systems, with a single VNF model predicting for all cluster sizes.

The results for the VNF model in the case of the Na cation are reported in the SM, Table S1 and Fig. S1. We again obtained low mean error, each time within the range of $1 \mathrm{~kJ} / \mathrm{mol}$ and in some cases of one order of magnitude lower with respect to the results for the chlorine presented here.

The results obtained for VNF are comparable to those obtained for kriging with a fixed number of features (see Tables 1 and 3). The mean error is the same in both cases and some differences can be seen only for the maximum error, which represent outlier points, without any clear trend (e.g. error is constantly higher in one model compared to another). From this, it follows that the differences in maximum error that we observe can be due to the particular training set choice and not to any differences in the models. This behaviour is expected since the VNF model is built to minimize the effect of the dummy features on the real training set, and here we showed how the VNF could be effective and flexible in obtaining kriging models.

The current work confirms and extends the previous work from our lab ${ }^{14}$. In our previous work the kriging predictions for only the electrostatic energy for water clusters was presented and only for $\mathrm{Na}^{+}$. In the current work we show results for larger clusters, up to seven water molecules, and pleasingly, results for chlorine are now also reported for the first time. More importantly, we calculated kriging models for IQA components of the energy, which completes the energy analysis except for dynamical electron 
correlation. The latter, from which one can derive dispersion energies, will be included in future ionwater models following the recently developed route $39-42$ of MP2-IQA.

\section{CONCLUSION}

The results presented here represent the first training for FFLUX of a hydrated ionic system. Hydrated ions are of primary importance for biological systems but at the same time they pose many challenges in their modelling because of the strong interactions exerted on the surrounding. In this work we report a proof-of-concept of the ability of kriging to be able to handle this kind of system. The kriging models are shown to reliably predict the interactions of an ionic, atomistic system with the energetic detail of expensive $a b$ initio calculations, without the need to perform the calculation during the simulation. Furthermore, by creating VNF models, accurate predictions were obtained for a variety of system sizes without the need to actually consider a single model for each arrangement of molecule that could possibly be seen in a simulation of such kind of systems. The Variable Number of Features (VNF) models increase the flexibility of the kriging predictions because we have shown that one single kriging model is able to keep into account all the cluster sizes. Thus, this work presents an important advancement towards the extension of FFLUX beyond its original protein remit, and the application of kriging models to molecular dynamics simulations of charged systems, in general, given FFLUX's generic nature.

\section{Supplementary Material}

See supplementary material for Table $S 1$ (Validation metrics for predictions of $V_{c l}\left(A, A^{\prime}\right) / 2, V_{x c}\left(A, A^{\prime}\right) / 2$,

$\mathrm{E}_{\text {intra }}$ for Na with VNF model. Different kriging models were used for each cluster size) and Figure S1 (Scurves for the $V_{c l}\left(A, A^{\prime}\right) / 2, V_{x c}\left(A, A^{\prime}\right) / 2$ and $E_{i n t r a}$, components of the IQA energy for the Na ion with the VNF model in all the clusters size considered).

\section{Acknowledgements}

All three authors thank the EPSRC for funding through the award of an Established Career Fellowship (grant EP/K005472).

\section{References}

${ }^{1}$ P. Jungwirth, D. J. Tobias, J.Phys.Chem.B 106, 6361 (2002).

${ }^{2}$ C. G. Baumann, S. B. Smith, V. A. Bloomfield, C. Bustamante, PNAS 94, 6185 (1997).

${ }^{3}$ K. Chakraborty, S. Khatua, S. Bandyopadhyay, PhysChemChemPhys 18, 15899 (2016).

${ }^{4}$ M. T. J. Record, E. Guinn, L. Pegram, M. Capp, Faraday Discuss. 160, 9 (2012).

${ }^{5}$ P. Raiteri, J. D. Gale, D. Quigley, P. M. Rodger, J.Phys.Chem.C 114, 5997 (2010).

${ }^{6}$ C. Zhang, S. Raugei, B. Eisenberg, P. Carloni, J.Chem. Theor.Comput. 6, 2167 (2010). 
${ }^{7}$ P. Raiteri, R. Demichelis, J. D. Gale, J.Phys.Chem.C 119, 24447 (2015).

${ }^{8}$ F. Moučka, I. Nezbeda, W. R. Smith, J.Chem.Phys. 139, 124505 (2013).

${ }^{9}$ L. A. P. Paul, Physica Scripta 91, 033007 (2016).

${ }^{10}$ K. Hansen, G. Montavon, F. Biegler, S. Fazli, M. Rupp, M. Scheffler, O. A. von Lilienfeld, T. Tkatchenko, K.-R. Mueller, J.Chem. Theory Comput. 9, 3404 (2013).

${ }^{11}$ A. P. Bartok, M. J. Gillan, F. R. Manby, G. Csanyi, Phys.Rev.B 88, 054104 (2013).

${ }^{12}$ G. A. Cisneros, K. T. Wikfeldt, L. Ojamäe, J. Lu, Y. Xu, H. Torabifard, A. P. Bartók, G. Csányi, V. Molinero, F. Paesani, Chem.Rev. 116, 7501 (2016).

${ }^{13}$ P. Bajaj, A. W. Goetz, F. Paesani, J.Chem. Theory Comput. 12, 2698 (2016).

${ }^{14}$ M. J. L. Mills, G. I. Hawe, C. M. Handley, P. L. A. Popelier, Phys.Chem.Chem.Phys. 15, 18249 (2013).

${ }^{15}$ M. A. Blanco, A. Martín Pendás, E. Francisco, J.Chem.Theor.Comput. 1, 1096 (2005).

${ }^{16}$ S. J. Davie, N. Di Pasquale, P. L. A. Popelier, J.Chem.Phys. 145, 104104 (2016).

${ }^{17}$ D. van der Spoel, E. Lindahl, B. Hess, G. Groenhof, A. E. Mark, H. J. C. Berendsen, J.Comp.Chem. 26, 1701 (2005).

${ }^{18}$ H. J. C. Berendsen, D. van der Spoel, R. van Drunen, Comp.Phys.Commun. 91, 43 (1995).

${ }^{19}$ U. Essmann, L. Perera, M. L. Berkowitz, T. Darden, H. Lee, L. G. Pedersen, The Journal of Chemical Physics 103, (1995).

${ }^{20}$ T. Darden, D. York, L. Pedersen, J.Chem.Phys. 98, 10089 (1993).

${ }^{21}$ H. J. C. Berendsen, J. R. Grigera, T. P. Straatsma, J.Phys.Chem. 91, 6269 (1987).

22 M. Christen, P. H. Huenenberger, D. Bakowies, R. Baron, R. Buergi, D. P. Geerke, T. N. Heinz, M. A. Kastenzholz, V. Kraeutler, C. Oostenbrink, C. Peter, D. Trzesniak, W. F. Van Gunsteren, J.Comp.Chem. 26, 1719 (2005).

${ }^{23}$ T. L. Fletcher, S. J. Davie, P. L. A. Popelier, J.Chem. Theory Comput. 10, 3708 (2014).

${ }^{24}$ M. J. Frisch, G. W. Trucks, H. B. Schlegel, G. E. Scuseria, M. A. Robb, J. R. Cheeseman, G. Scalmani, V. Barone, B. Mennucci, G. A. Petersson, H. Nakatsuji, M. Caricato, X. Li, H. P. Hratchian, A. F. Izmaylov, J. Bloino, G. Zheng, J. L. Sonnenberg, M. Hada, M. Ehara, K. Toyota, R. Fukuda, J. Hasegawa, M. Ishida, T. Nakajima, Y. Honda, O. Kitao, H. Nakai, T. Vreven, J. A. Montgomery, J. E. Peralta, F. Ogliaro, M. Bearpark, J. J. Heyd, E. Brothers, K. N. Kudin, V. N. Staroverov, R. Kobayashi, J. Normand, K. Raghavachari, A. Rendell, J. C. Burant, S. S. Iyengar, J. Tomasi, M. Cossi, N. Rega, J. M. Millam, M. Klene, J. E. Knox, J. B. Cross, V. Bakken, C. Adamo, J. Jaramillo, R. Gomperts, R. E. Stratmann, O. Yazyev, A. J. Austin, R. Cammi, C. Pomelli, J. W. Ochterski, R. L. Martin, K. Morokuma, V. G. Zakrzewski, G. A. Voth, P. Salvador, J. J. Dannenberg, S. Dapprich, A. D. Daniels, Farkas, J. B. Foresman, J. V. Ortiz, J. Cioslowski, D. J. Fox. (Wallingford CT, 2009).

${ }^{25}$ P. Maxwell, A. Martín Pendás, P. L. A. Popelier, PhysChemChemPhys 18, 20986 (2016).

${ }^{26}$ T. A. Keith, AIMAll (Version 13.10.19), (http://aim.tkgristmill.com), T. G. S. Todd A. Keith, Overland Park KS, USA, (aim.tkgristmill.com). (2013). 
${ }^{27}$ P. L. A. Popelier, D. S. Kosov, J.Chem.Phys. 114, 6539 (2001).

${ }^{28}$ P. Maxwell, N. di Pasquale, S. Cardamone, P. L. A. Popelier, Theor.Chem.Acc. 135, 195 (2016).

${ }^{29}$ N. Di Pasquale, M. Bane, S. J. Davie , P. L. A. Popelier, J.Comput.Chem. 37, 2606 (2016).

${ }^{30}$ N. Di Pasquale, S. J. Davie, P. L. A. Popelier, J.Chem. Theor.Comp. 12, 1499 (2016).

${ }^{31}$ D. R. Jones, M. Schonlau, W. J. Welch, J.Global Optim. 13, 455 (1998).

${ }^{32}$ S. M. Kandathil, T. L. Fletcher, Y. Yuan, J. Knowles, P. L. A. Popelier, J.Comput.Chem. 34, 1850 (2013).

${ }^{33}$ M. J. L. Mills, P. L. A. Popelier, Theor.Chem.Acc. 131, 1137 (2012).

${ }^{34}$ S. J. Davie, N. Di Pasquale, P. L. A. Popelier, J.Comput.Chem. 37, 2409 (2016).

35 J. Behler, J.Phys.Condens. Matter 26, 183001 (2014).

${ }^{36}$ P. K. Ojha, I. Mitra, R. N. Das, K. Roy, Chemometrics \& Intell. Lab.Syst. 107, 194 (2011).

${ }^{37}$ G. Rennen, Struct. Multidisc.Optim. 38, 545 (2009).

${ }^{38}$ D. H. Powell, A. C. Barnes, J. E. Enderby, G. W. Neilson, P. S. Salmon, Faraday Discussion 85, 137 (1988).

39 A. F. Silva, M. A. Vincent, J. L. McDonagh, P. L. A. Popelier, ChemPhysChem 18, DOI: 10.1002/cphc.201700890 (2017).

${ }^{40}$ M. A. Vincent, A. F. Silva, J. L. McDonagh, P. L. A. Popelier, Int.J.Quant.Chem. DOI: 10.1002/qua.25519, (2018).

${ }^{41}$ J. L. McDonagh, M. A. Vincent, P. L. A. Popelier, Chem.Phys.Lett. 662, 228 (2016).

42 J. L. McDonagh, A. F. Silva, M. A. Vincent, P. L. A. Popelier, J.Phys.Chem.Letts. 8, 1937 (2017). 



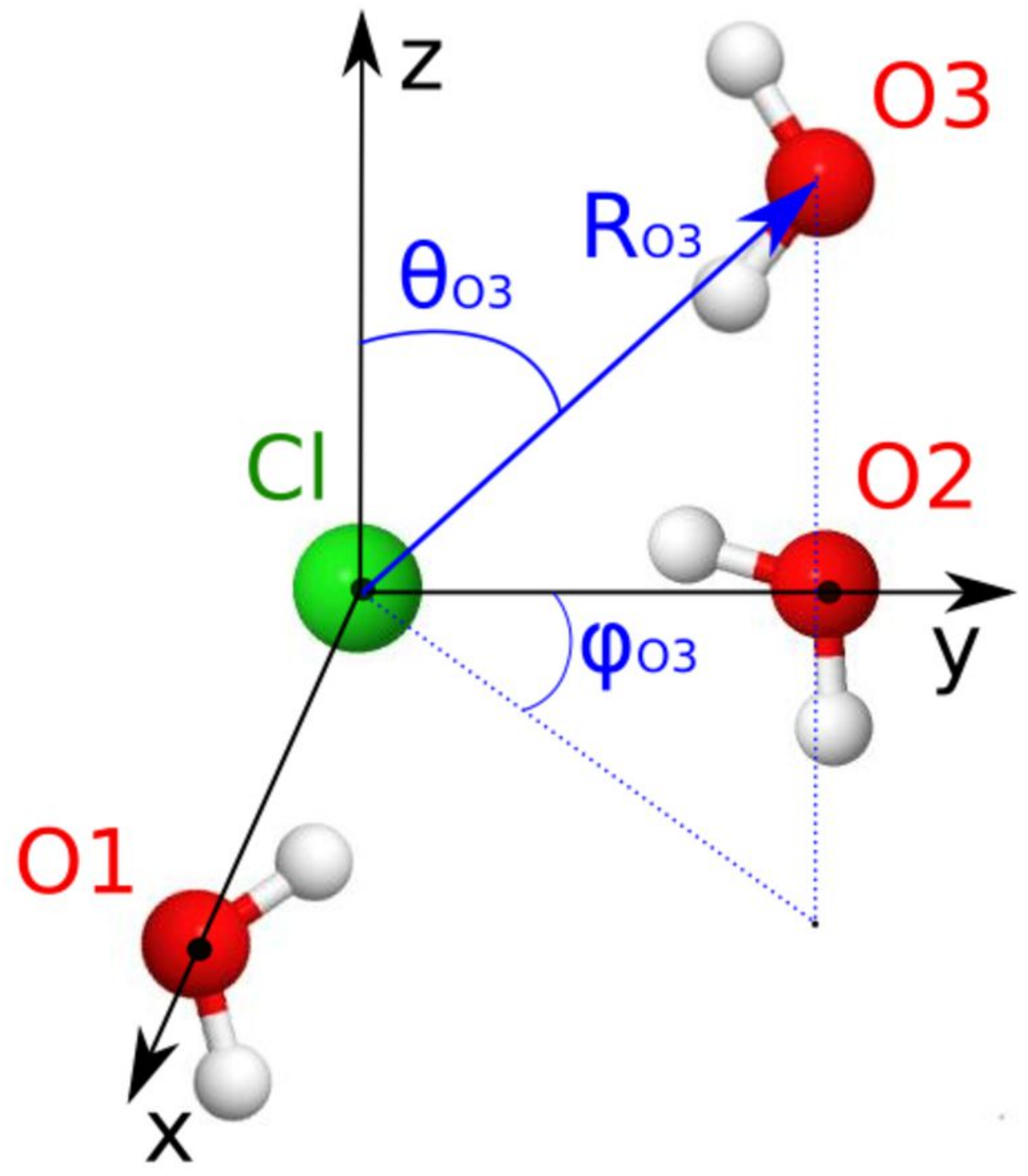



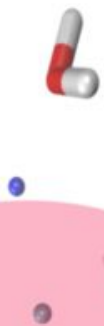


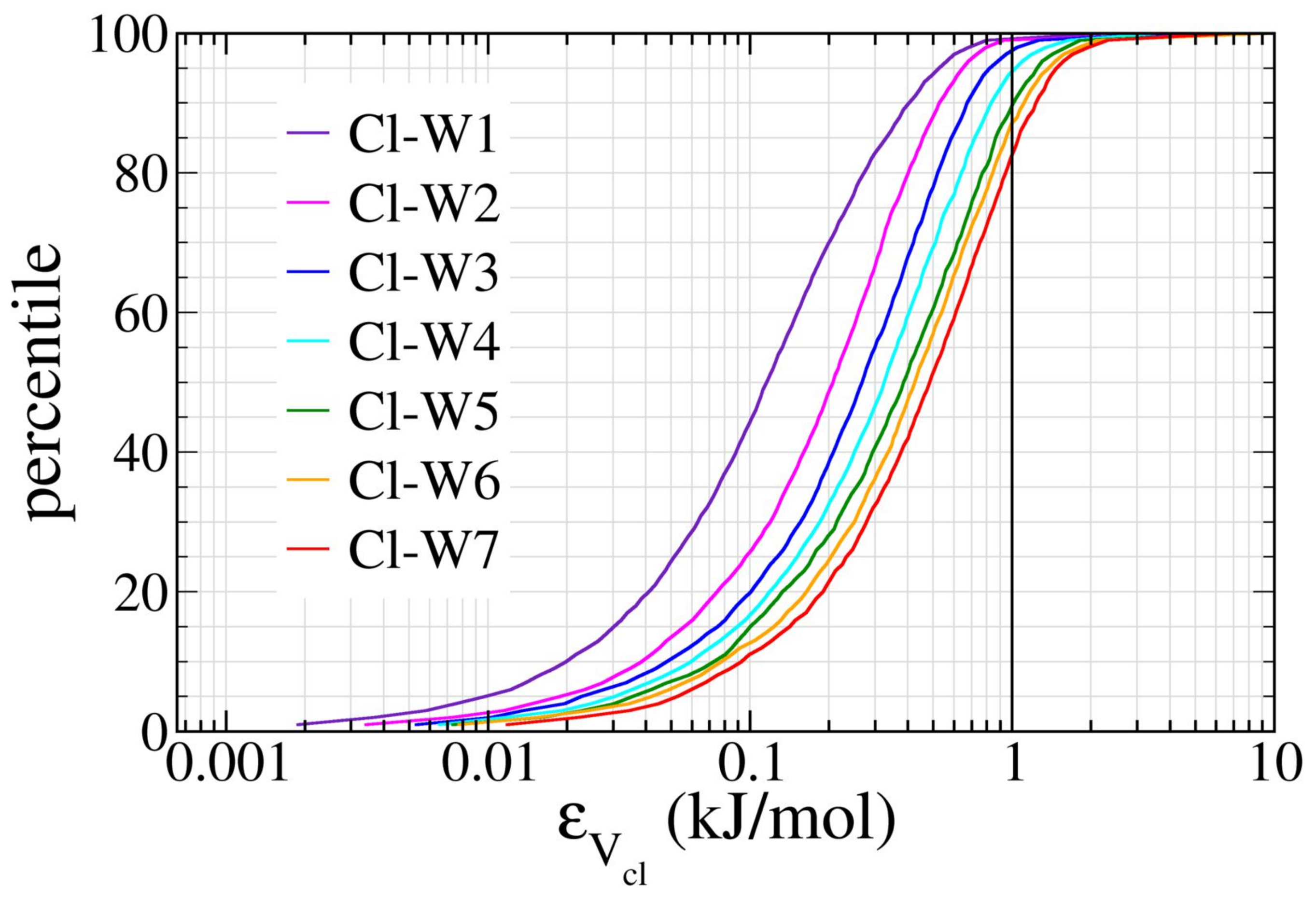




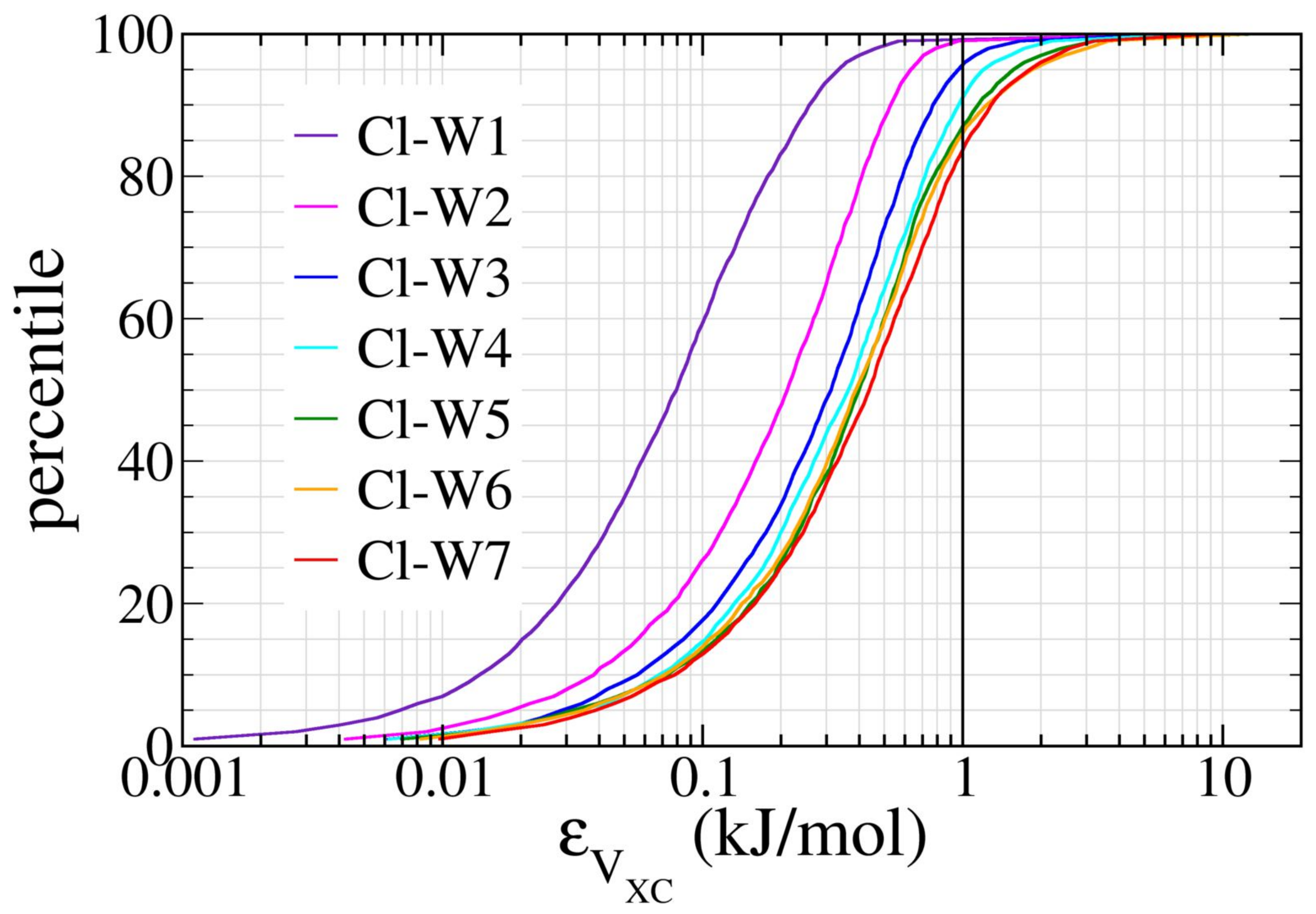




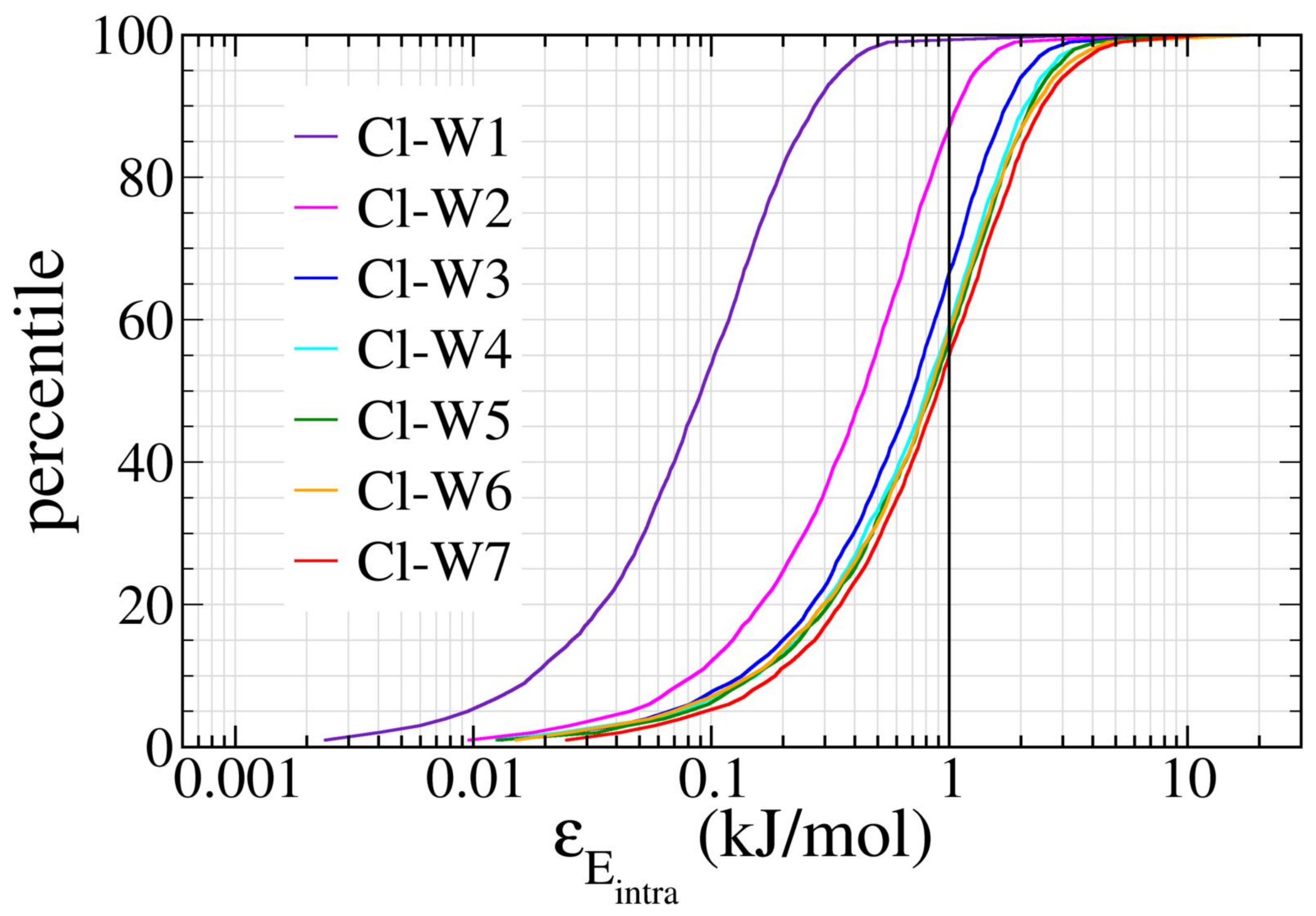




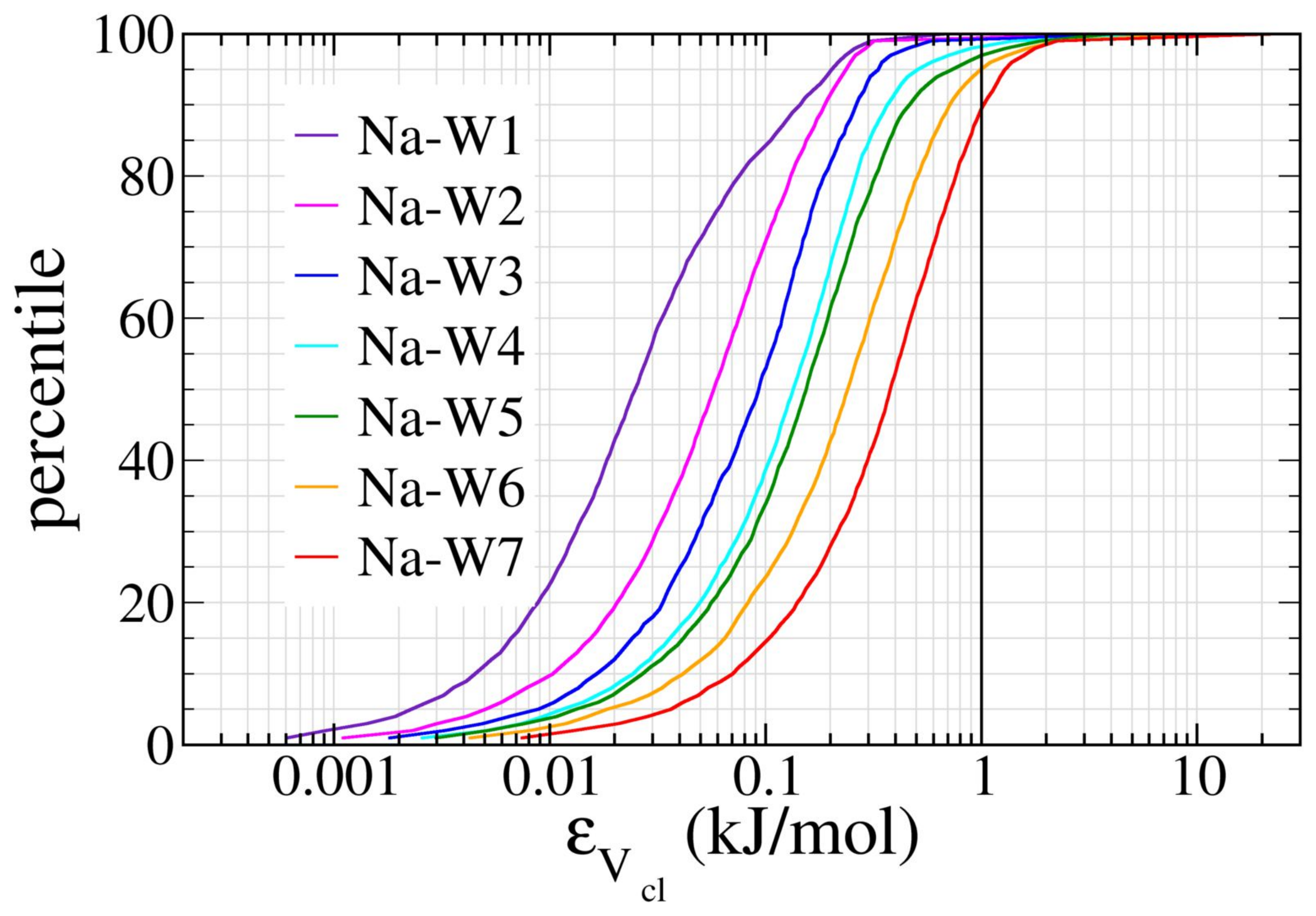




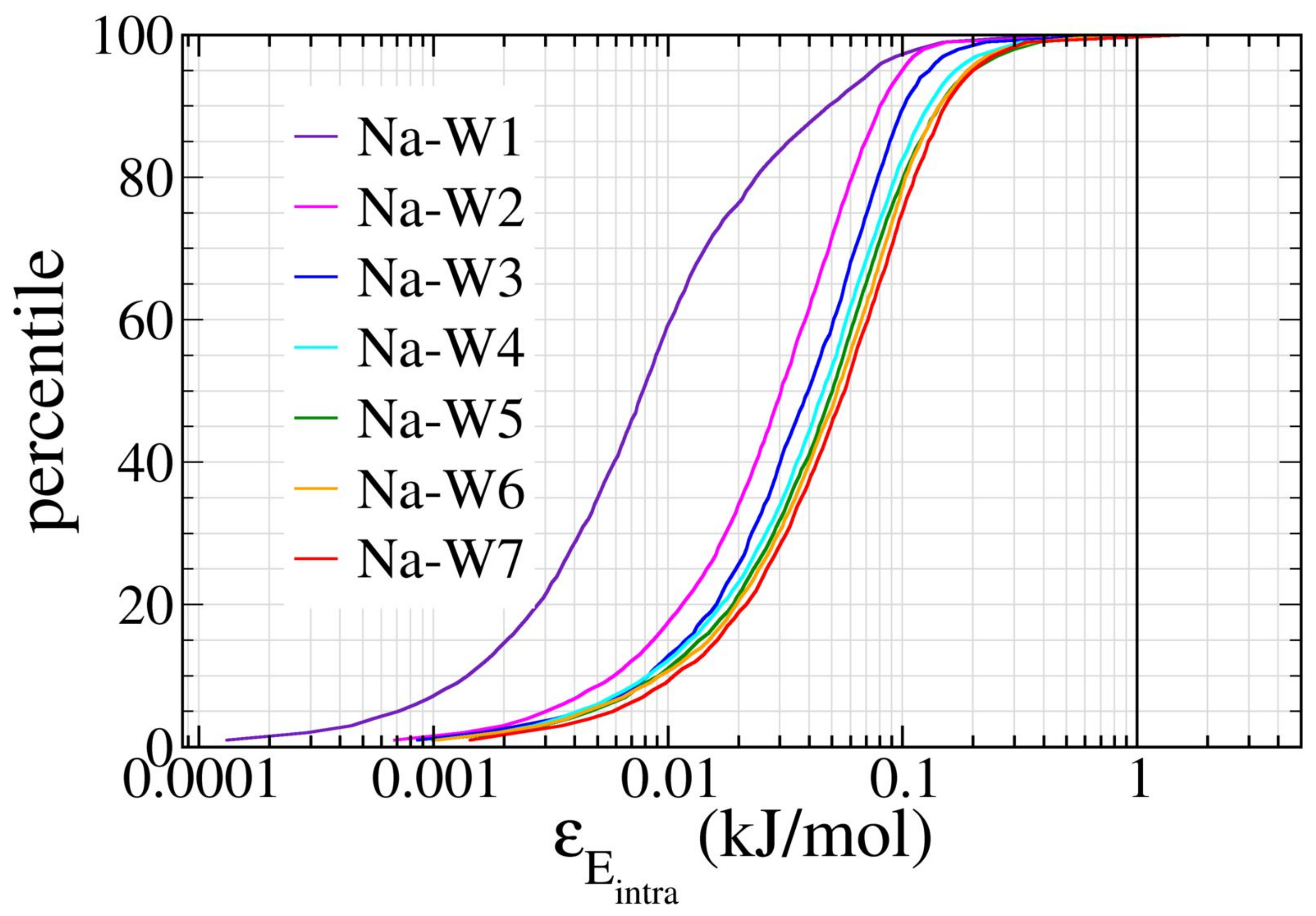




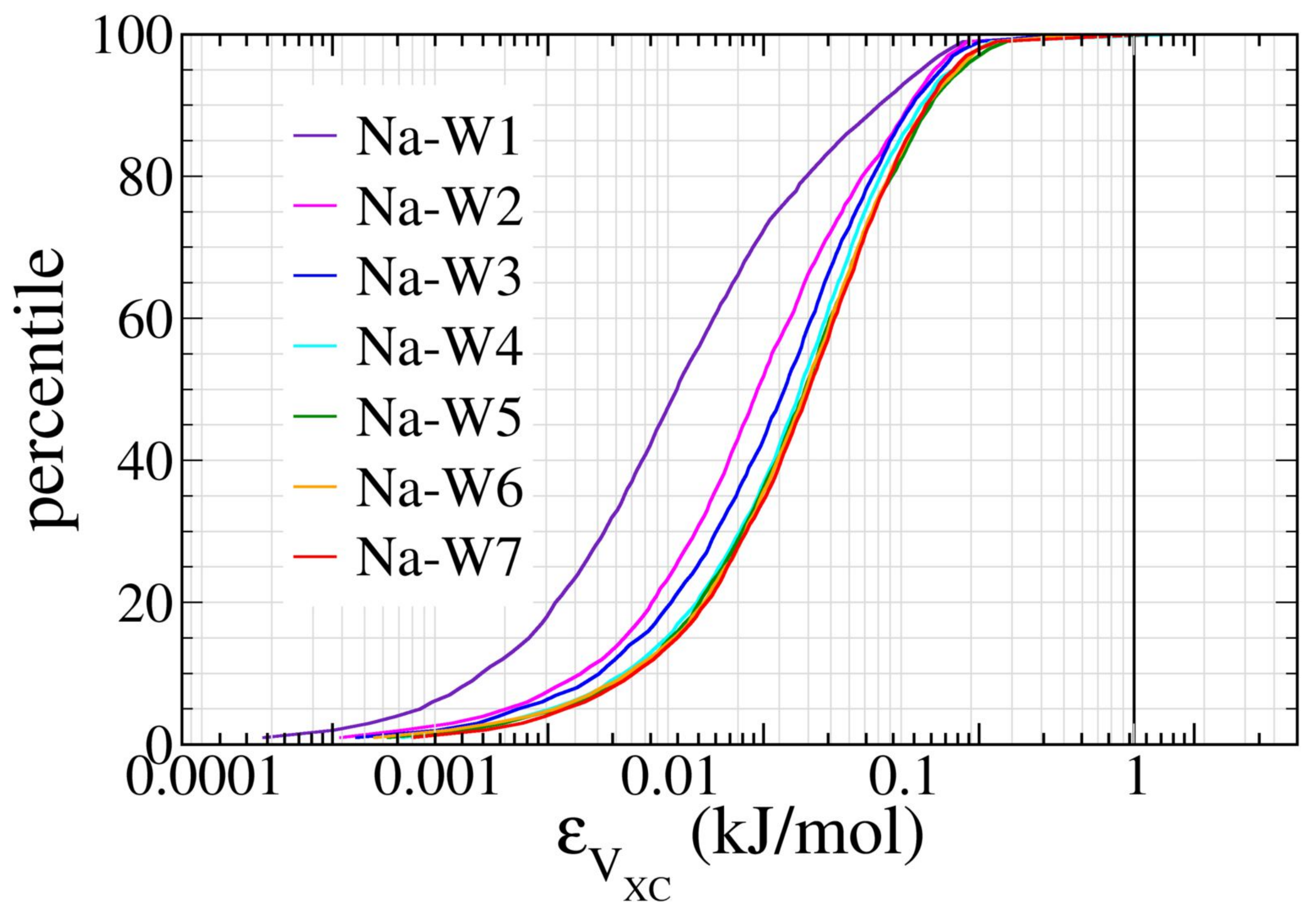




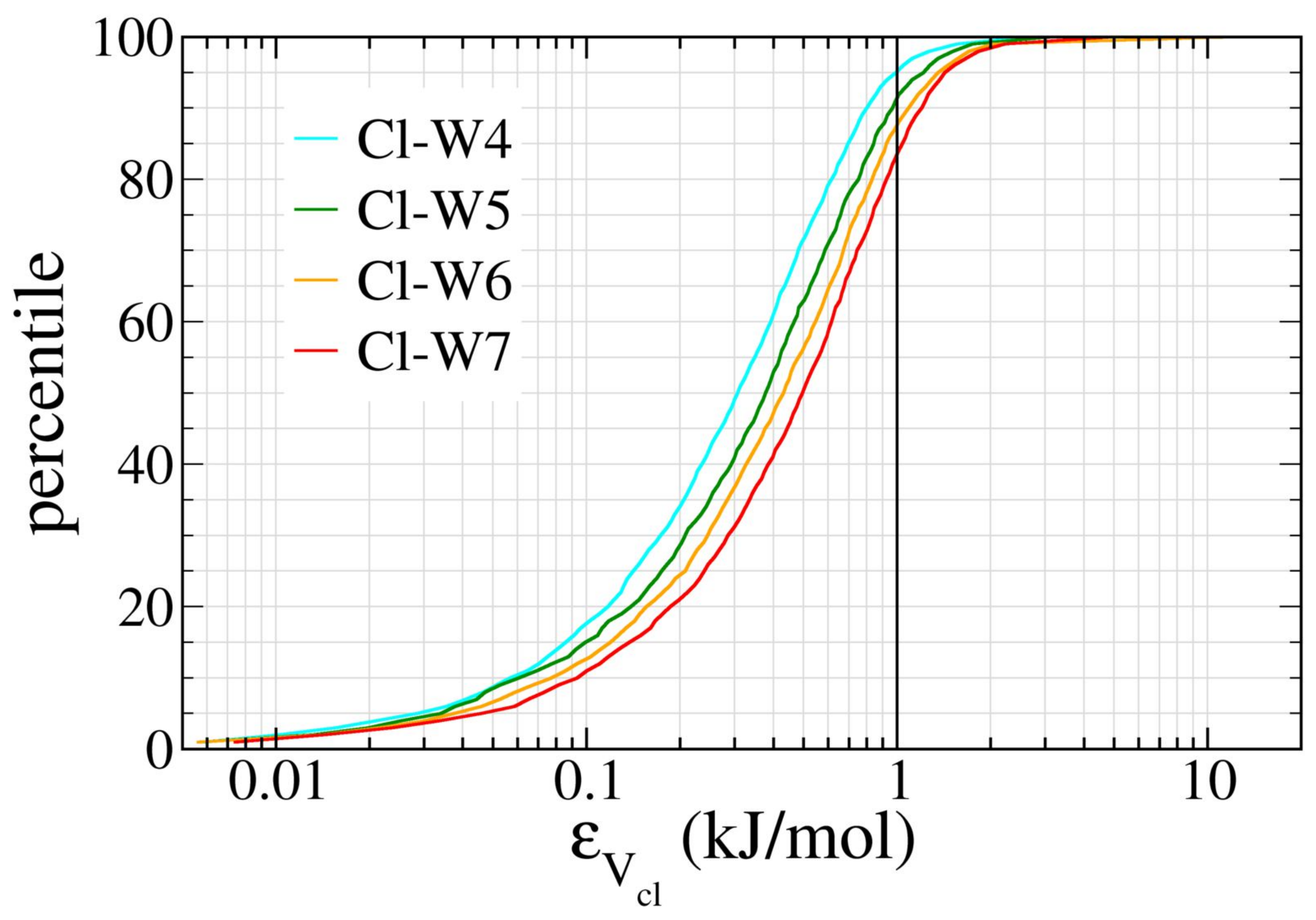




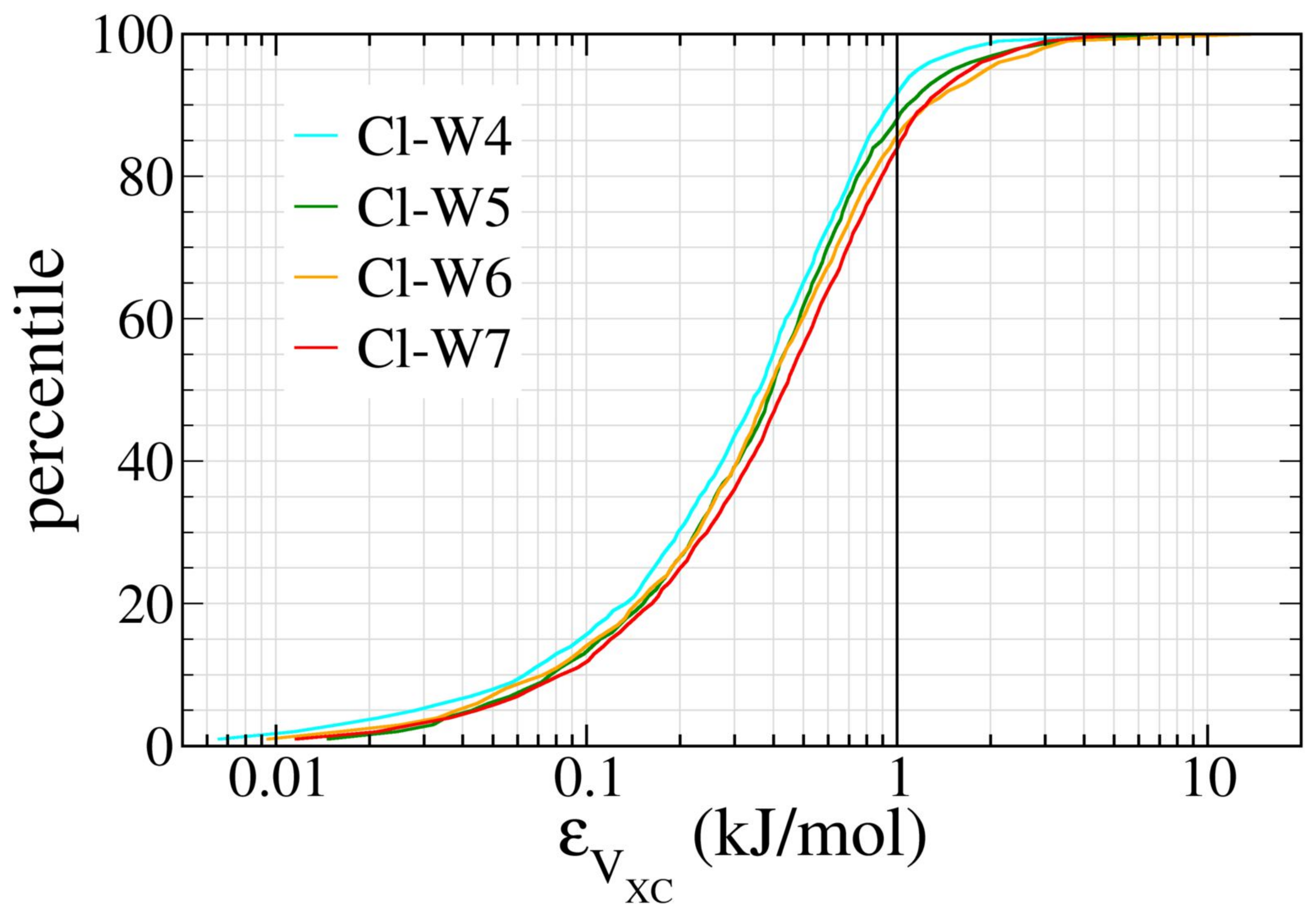




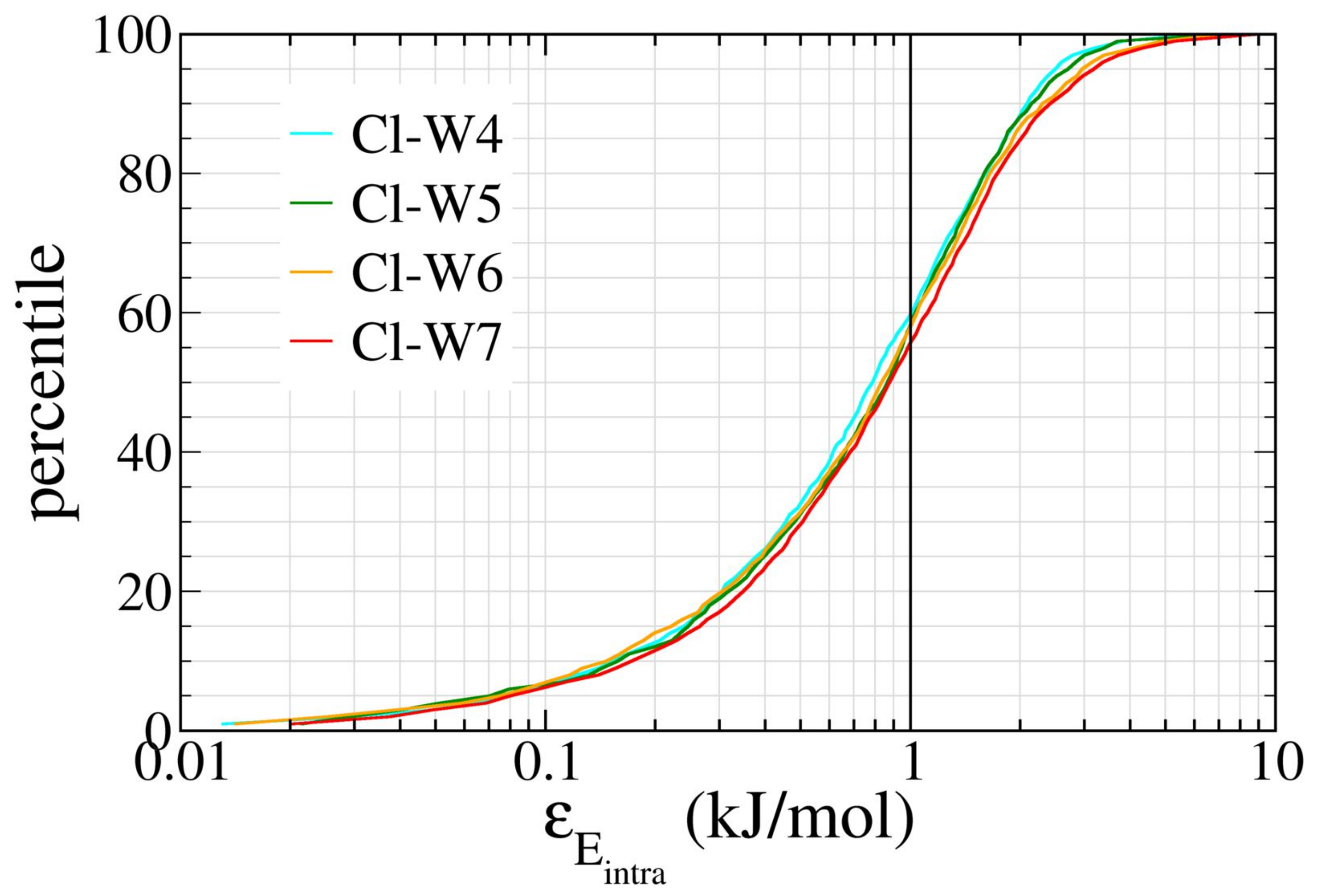

